HEPATOBILIARY

\title{
Familial liver and gall bladder cancer: a nationwide epidemiological study from Sweden
}

\section{K Hemminki, X Li}

See end of article for authors' affiliations

Correspondence to:

K Hemminki, CNT Novum, 141 57, Sweden;

kari.hemminki@cnt.ki.se

Accepted for publication 18 October 2002

\begin{abstract}
Background and aims: Familial risks in liver and biliary cancers have been assessed in small case control studies, usually based on reported, but not medically verified, cancers in family members. Thus the degree of familial clustering for these cancers remains to be established.

Methods: The nationwide Swedish Family-Cancer Database was used, covering 10.2 million individuals for the years 1961-1998 from the Swedish Cancer Registry. Liver and biliary tract cancers were identified from 1121 offspring between the ages of 0 and 66 years and 17131 parents. Standardised incidence ratios (SIRs) and $95 \%$ confidence intervals $(\mathrm{Cls})$ were calculated for cancers in family members.

Results: All cancers in the liver and biliary system showed a familial SIR of $1.65(95 \% \mathrm{Cl} 1.05-2.46)$. This was mainly explained by a high risk for familial gall bladder cancer (SIR $5.21 \quad 195 \%$ CI 2.07-10.80)! and for familial primary liver cancer with hepatocellular carcinoma histology (SIR 4.69 (95\% Cl 1.48-1 1.04)). For gall bladder and hepatocellular cancer, maternal transmission appeared to be favoured. Gall bladder cancer was associated with pancreatic cancer (SIR $2.39195 \% \mathrm{Cl} 1.23-$ 4.18)). Primary liver cancer was associated with cervical, urinary bladder, and endocrine gland tumours. Cancer in extrahepatic bile ducts was associated with ovarian cancer and that in ampulla of Vater with thyroid cancer; however, these associations may have been fortuitous.

Conclusions: This study has provided the first data on familial clustering of liver and gall bladder cancers, based on medically confirmed records. The risks were so high that heritable factors were likely to contribute, possibly modified by environmental factors. The demonstration of candidate genes would help to further characterise the familial risks.
\end{abstract}

T he International Classification of Diseases revision 7 (ICD-7) distinguishes four groups of primary liver and biliary tract tumours by organ sites under code 155: liver (ICD-7 code 155.0), gall bladder (155.1), extrahepatic bile ducts (155.2), and ampulla of Vater (155.3). The incidence of the first two is approximately $5 / 100000$ and that of the latter two below 1/100 00 in Sweden, but the rates show wide international variations depending on the distribution of the environmental risk factors. ${ }^{1-3}$ Sweden, northern Europe, and the White US population belong to low risk areas because of the low prevalence of the risk factors: chronic infection by hepatitis $\mathrm{B}$ or $\mathrm{C}$ virus, cholangiogenic liver flukes, ingestion of aflatoxin Bl mycotoxin, and alcohol induced liver cirrhosis. ${ }^{24}$ The international variation in incidence is less dramatic for gall bladder cancer for which gall stones and some structural abnormalities are known risk factors. ${ }^{2}$ Hepatocellular carcinoma is a manifestation of some rare inherited metabolic diseases, such as porphyria cutanea tarda and inherited haemochromatosis. The biliary tract and gall bladder are affected in hereditary non-polyposis colorectal cancer (HNPCC),,$^{25}$ and the risk has been estimated to be almost 10 -fold in mutation carriers, based on small numbers however. ${ }^{6}$ Familial aggregation of hepatocellular carcinoma has been observed in high risk areas and chronic hepatitis B carries, but to what extent the results show shared environment or inherited susceptibility remains unknown. ${ }^{78}$ Case reports of familial aggregation of liver cancer, and ethnic differences in the incidence, have been used as an argument for familial risk, but neither type of evidence can prove the case. ${ }^{29}$ In one epidemiological study, a 2.4-fold risk of liver cancer was observed between first degree relatives. ${ }^{10}$ In this study, one familial case of gall bladder cancer was also noted whereas no increase was observed in another study. ${ }^{11}$ Data from the Swedish Family-Cancer Database have never been analysed separately for organs belonging to the ICD-7 code 155, but these organs combined have been associated with pancreatic and cervical cancers. ${ }^{12}$

Because of the scant population based data on familial clustering of liver and biliary cancers, we examined familial risks using the nationwide Swedish Family-Cancer Database..$^{14}$ The Database was updated in 2001 to include over 10 million individuals and over one million registered tumours. It offers unique possibilities for reliable estimation of familial risks because the data on family relationships and cancers were obtained from registered sources. The present study covered 18252 patients with liver and biliary tumours, compared with the previous case control study on 378 patients and 1408 controls. $^{10}$

\section{SUBJECTS AND METHODS}

The Swedish Family-Cancer Database was initially created in the middle of the 1990s by linking an administrative family register on all Swedish families to the Swedish Cancer Registry. ${ }^{14}{ }^{15}$ For each child there are data on both parents at the time of birth. Each person is assigned a unique technical identification number (which is different from the national identification number, "personal number") allowing construction of families, for example, through the mother. The Database includes all persons born in Sweden after 1931 with their biological parents, totalling over 10.2 million individuals. It was updated in 2000 to include cancers from the nationwide Swedish Cancer Registry from the years 1958-1998. The Database covers 3.2 million families, with parents and offspring.

Abbreviations: HNPCC, hereditary non-polyposis colorectal cancer; SIR, standardised incidence ratio; SNOMED, Systematised Nomenclature of Medicine. 
Table 1 Number of liver and biliary cancers in offspring and parents

\begin{tabular}{|c|c|c|c|c|c|c|c|c|}
\hline \multirow[b]{2}{*}{ Cancer site (ICD-7) } & \multirow[b]{2}{*}{ Son cases } & \multirow[b]{2}{*}{ Daughter cases } & \multicolumn{2}{|c|}{ Offspring } & \multirow[b]{2}{*}{ Father cases } & \multirow[b]{2}{*}{ Mother cases } & \multicolumn{2}{|l|}{ Parents } \\
\hline & & & Cases & $\%$ & & & Cases & $\%$ \\
\hline Liver, primary (155.0) & 326 & 230 & 556 & 49.6 & 4358 & 2476 & 6834 & 39.9 \\
\hline Gall bladder (155.1) & 92 & 220 & 312 & 27.8 & 1880 & 4904 & 6784 & 39.6 \\
\hline Extrahepatic bile ducts (155.2) & 48 & 54 & 102 & 9.1 & 908 & 1025 & 1933 & 11.3 \\
\hline Ampulla of Vater (155.3) & 51 & 30 & 81 & 7.2 & 465 & 333 & 798 & 4.7 \\
\hline All (155) & 552 & 569 & 1121 & 100.0 & 7906 & 9216 & 17131 & 100.0 \\
\hline
\end{tabular}

The completeness of cancer registration for the 1970s has been estimated as over $95 \%$, and is now considered to be close to $100 \%$. The percentage of cytologically or histologically verified cases of primary liver and biliary cancers has been calculated as over $95 \%$ throughout the operation of the Swedish Cancer Registry. ${ }^{3}$ In an ad hoc study on gastric adenocarcinoma, the completeness of the Cancer Registry was found to be $98 \%{ }^{16}$ The Family-Cancer Database has an incomplete linkage from deceased offspring to parents, particularly among those offspring born between 1932 and $1940 .{ }^{14}$ Of a total of 7.0 million offspring, 216000 died by the end of follow up at 31 December 1998. Parental information was missing from 15000 offspring who had a diagnosis of cancer $(9.9 \%$ of all offspring cancers). This deficit is likely to cause some inaccuracies of familial risk estimates in the present study because the analysed cancers have high mortality. However, because most of the subjects with incomplete parental information were born in the 1930s or died before 1991, we have shown elsewhere that almost all familial cases of liver and biliary tract cancers come from the period of minimal lack of data. ${ }^{17}$

The Swedish Cancer Registry is based on compulsory notification of cases. ${ }^{3}$ Primary liver and biliary tumours by organ sites covered by code 155 were liver (ICD-7 code 155.0), gall bladder (155.1), extrahepatic bile ducts (155.2), and ampulla Vater (155.3). From 1993 onwards, ICD-O-2/ICD-IO with histopathological data according to the Systematised Nomenclature of Medicine (SNOMED, http://snomed.org) was used; we refer to this classification as "histopathology". The following ICD-7 codes were pooled in analyses between tumour sites: "upper aerodigestive tract" cancer, codes 161 (larynx) and 140-148 (lip, mouth, pharynx), except for code 142 (salivary glands), and "leukaemia," codes 204-207 (leukaemias), 208 (polycythemia vera), and 209 (myelofibrosis). According to the ICD-7 classification, lymphomas are classified as lymphomas irrespective of the site at which they occur.

Information on family history was collected on all first degree relatives (parents, siblings, and children) but only the parent-offspring relationship was used in the present study because of the lack of affected sibling pairs. All tumour incidence rates were based on data in the Family-Cancer Database. Age standardisation to the European standard population was performed. The risk of liver cancer was calculated for offspring whose parents presented with liver cancer (parents as probands) or any other specified tumour, and their risk was compared with the rate of these cancers among all offspring. Some calculations were done in reverse order- that is, offspring as probands; person years were then calculated for parents. Results were tabulated if at least five familial pairs were found for an ICD-7 site. Follow up was started at birth or 1 January 1961, whichever was latest. Follow up was terminated on cancer diagnosis, death, emigration, or the closing data of the study (31 December 1998). Standardised incidence ratios (SIRs) were calculated as the ratio of observed (O) to expected (E) number of cases. The expected numbers were calculated from five year age, sex, tumour type, region, period, and socioeconomic status specific SIRs. Confidence intervals (95\% CI) were calculated assuming a Poisson distribution.

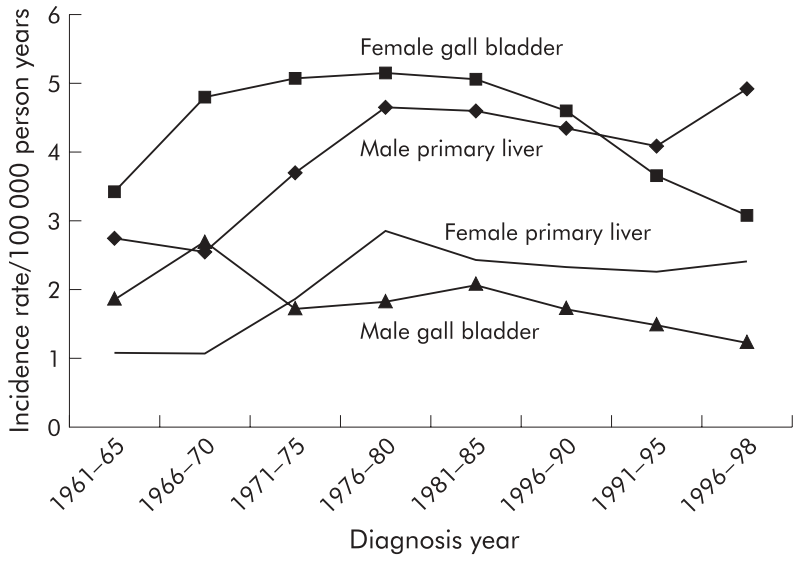

Figure 1 Age standardised incidence of primary liver and gall bladder cancer in men and women from the Swedish Family-Cancer Database for the years 1961-1998.

\section{RESULTS}

The Family-Cancer Database covered the years 1961-1998 from the Swedish Cancer Registry and included 1121 offspring between the ages of 0 and 66 years and 17131 parents with liver and biliary tract cancer (table 1). Liver cancer constituted $49.6 \%$ of offspring and $39.9 \%$ of parental cases. For gall bladder, the percentages were $27.8 \%$ and $39.6 \%$, respectively. The incidence trends for these two most common cancers for all men and women in the Database are shown in fig 1 for the period spanning 1961-1998. The incidence of liver cancer increased and that of gall bladder cancer decreased over this period. There was a more than twofold male excess in the former and an even larger female excess in the latter. For tumours of the extrahepatic bile ducts, there was no difference between the sexes but for those at the ampulla of Vater there was an almost twofold male excess (data not shown).

Familial risks for offspring liver and biliary tract cancer were calculated by parental cancer (parents as probands, table 2 ). The data in this and subsequent tables were adjusted for age, period, residential area, and socioeconomic status, all of which may influence the incidence of these cancers. Only those cancer sites which showed an association with at least five offspring liver and biliary tract cancers are listed in table 2. The SIR for liver and biliary tract cancer in offspring was 2.11 (95\% CI 1.25-3.34) when a mother presented with liver and biliary tract cancer. However, from all parents, the SIR was less (1.65 (1.05-2.46)). Offspring liver and biliary cancer was increased from upper aerodigestive tract and pancreatic cancer in fathers and in all parents. Parental endocrine gland tumours were associated with liver and biliary tract cancers in offspring, giving the highest SIR (2.34). These associated specifically with parathyroid tumours (SIR 2.92 (7, 1.16-6.06)). Maternal kidney cancer was also a risk factor for liver and biliary tract cancer in offspring.

In table 3, SIRs for organ sites under ICD-7 code 155 were first scrutinised for offspring by parental probands and then 
Table 2 Standardised incidence ratios (SIRs) for liver and biliary cancer in offspring by cancer in parents

\begin{tabular}{|c|c|c|c|c|c|c|c|c|c|c|c|c|}
\hline \multirow{3}{*}{$\begin{array}{l}\text { Parental cancer } \\
\text { Upper aerodigestive tract }\end{array}$} & \multicolumn{4}{|c|}{ Father } & \multicolumn{4}{|c|}{ Mother } & \multicolumn{4}{|c|}{ Parents } \\
\hline & \multirow{2}{*}{$\frac{0}{19}$} & \multirow{2}{*}{\begin{tabular}{|l|} 
SIR \\
2.20
\end{tabular}} & \multicolumn{2}{|c|}{$95 \% \mathrm{Cl}$} & \multirow{2}{*}{$\frac{0}{1}$} & \multirow{2}{*}{$\frac{\text { SIR }}{0.37}$} & \multicolumn{2}{|c|}{$95 \% \mathrm{Cl}$} & \multirow{2}{*}{$\frac{0}{20}$} & \multirow{2}{*}{$\frac{\operatorname{SIR}}{1.76}$} & \multicolumn{2}{|c|}{$95 \% \mathrm{Cl}$} \\
\hline & & & 1.32 & 3.45 & & & 0.00 & 2.10 & & & 1.07 & 2.73 \\
\hline Stomach & 19 & 0.98 & 0.59 & 1.54 & 10 & 1.05 & 0.50 & 1.94 & 29 & 1.01 & 0.67 & 1.45 \\
\hline Small intestine & 2 & 1.86 & 0.17 & 6.83 & 3 & 3.09 & 0.58 & 9.16 & 5 & 2.44 & 0.77 & 5.75 \\
\hline Colon & 16 & 0.90 & 0.51 & 1.46 & 16 & 0.85 & 0.48 & 1.38 & 32 & 0.87 & 0.60 & 1.23 \\
\hline Rectum & 14 & 1.13 & 0.62 & 1.90 & 14 & 1.60 & 0.87 & 2.69 & 28 & 1.33 & 0.88 & 1.92 \\
\hline Liver and biliary & 6 & 0.99 & 0.36 & 2.18 & 18 & 2.11 & 1.25 & 3.34 & 24 & 1.65 & 1.05 & 2.46 \\
\hline Pancreas & 19 & 2.22 & 1.33 & 3.47 & 7 & 0.90 & 0.36 & 1.86 & 26 & 1.59 & 1.04 & 2.33 \\
\hline Lung & 32 & 1.28 & 0.87 & 1.81 & 5 & 0.60 & 0.19 & 1.40 & 37 & 1.11 & 0.78 & 1.53 \\
\hline Breast & & & & & 46 & 0.95 & 0.69 & 1.26 & 46 & 0.94 & 0.69 & 1.25 \\
\hline Cervix & & & & & 15 & 1.48 & 0.82 & 2.44 & 15 & 1.48 & 0.82 & 2.44 \\
\hline Endometrium & & & & & 15 & 1.25 & 0.69 & 2.06 & 15 & 1.25 & 0.69 & 2.06 \\
\hline Ovary & & & & & 10 & 0.88 & 0.42 & 1.62 & 10 & 0.88 & 0.42 & 1.62 \\
\hline Prostate & 77 & 1.15 & 0.91 & 1.44 & & & & & 77 & 1.15 & 0.91 & 1.44 \\
\hline Kidney & 6 & 0.66 & 0.24 & 1.45 & 14 & 1.89 & 1.03 & 3.18 & 20 & 1.22 & 0.74 & 1.88 \\
\hline Urinary bladder & 26 & 1.50 & 0.98 & 2.20 & 6 & 1.18 & 0.43 & 2.59 & 32 & 1.43 & 0.98 & 2.02 \\
\hline Melanoma & 1 & 0.23 & 0.00 & 1.31 & 8 & 1.70 & 0.73 & 3.36 & 9 & 0.99 & 0.45 & 1.89 \\
\hline Skin & 7 & 0.71 & 0.28 & 1.46 & 10 & 1.61 & 0.77 & 2.97 & 17 & 1.05 & 0.61 & 1.69 \\
\hline Nervous system & 3 & 0.54 & 0.10 & 1.59 & 7 & 1.03 & 0.41 & 2.13 & 10 & 0.81 & 0.38 & 1.49 \\
\hline Thyroid gland & & & & & 5 & 1.92 & 0.61 & 4.53 & 5 & 1.39 & 0.44 & 3.26 \\
\hline Endocrine glands & 6 & 3.20 & 1.15 & 7.01 & 11 & 2.05 & 1.02 & 3.68 & 17 & 2.34 & 1.36 & 3.76 \\
\hline Non-Hodgkin's lymphoma & 6 & 0.91 & 0.33 & 1.98 & 4 & 0.67 & 0.18 & 1.74 & 10 & 0.80 & 0.38 & 1.47 \\
\hline Myeloma & 4 & 0.93 & 0.24 & 2.40 & 7 & 1.96 & 0.78 & 4.05 & 11 & 1.40 & 0.69 & 2.51 \\
\hline Leukaemia & 5 & 0.66 & 0.21 & 1.55 & 7 & 1.17 & 0.46 & 2.42 & 12 & 0.88 & 0.45 & 1.55 \\
\hline All & 268 & 1.15 & 1.01 & 1.29 & 239 & 1.19 & 1.04 & 1.35 & 507 & 1.16 & 1.07 & 1.27 \\
\hline
\end{tabular}

Values in bold type indicate that $95 \%$ confidence interval $(95 \% \mathrm{CI})$ does not include 1.00

O, observed.

Table 3 Standardised incidence ratios (SIRs) for cancer in the liver and biliary organs in offspring and parents

\begin{tabular}{|c|c|c|c|c|c|c|c|c|c|c|c|c|c|c|c|c|}
\hline \multirow{3}{*}{$\begin{array}{l}\text { Cancer } \\
\text { Parental cancer }\end{array}$} & \multicolumn{4}{|c|}{ Primary liver } & \multicolumn{4}{|c|}{ Gall bladder } & \multicolumn{4}{|c|}{ Extrahepatic bile ducts } & \multicolumn{4}{|c|}{ Ampulla of Vater } \\
\hline & \multirow[t]{2}{*}{0} & \multirow[t]{2}{*}{ SIR } & \multicolumn{2}{|c|}{$95 \% \mathrm{Cl}$} & \multirow[t]{2}{*}{0} & \multirow[t]{2}{*}{ SIR } & \multicolumn{2}{|c|}{$95 \% \mathrm{Cl}$} & \multirow[t]{2}{*}{0} & \multirow[t]{2}{*}{ SIR } & \multicolumn{2}{|c|}{$95 \% \mathrm{Cl}$} & \multirow[t]{2}{*}{0} & \multirow[t]{2}{*}{ SIR } & \multicolumn{2}{|c|}{$95 \% \mathrm{Cl}$} \\
\hline & & & & & & & & & & & & & & & & \\
\hline Liver and biliary & 8 & 1.26 & 0.54 & 2.50 & 14 & 3.13 & 1.70 & 5.26 & 1 & 0.70 & 0.00 & 3.99 & 1 & 0.79 & 0.00 & 4.53 \\
\hline Pancreas & 8 & 1.13 & 0.48 & 2.23 & 12 & 2.39 & 1.23 & 4.18 & 2 & 1.21 & 0.11 & 4.46 & 3 & 2.12 & 0.40 & 6.26 \\
\hline Cervix & 10 & 2.11 & 1.01 & 3.90 & 2 & 0.69 & 0.07 & 2.54 & 1 & 1.08 & 0.00 & 6.18 & 2 & 2.34 & 0.22 & 8.62 \\
\hline Ovary & 5 & 0.96 & 0.30 & 2.26 & 0 & & & & 4 & 3.83 & 1.00 & 9.91 & 1 & 1.02 & 0.00 & 5.82 \\
\hline Urinary bladder & 21 & 2.06 & 1.27 & 3.15 & 5 & 0.77 & 0.24 & 1.80 & 0 & & & & 1 & 0.52 & 0.00 & 3.00 \\
\hline Thyroid gland & 2 & 1.18 & 0.11 & 4.35 & 3 & 2.91 & 0.55 & 8.61 & 0 & & & & 0 & & & \\
\hline Endocrine glands & 8 & 2.34 & 1.00 & 4.64 & 3 & 1.47 & 0.28 & 4.35 & 2 & 3.01 & 0.28 & 11.07 & 2 & 3.33 & 0.31 & 12.26 \\
\hline \multicolumn{17}{|l|}{ Offspring cancer } \\
\hline Liver and biliary & 11 & 1.61 & 0.80 & 2.89 & 14 & 1.93 & 1.05 & 3.25 & 2 & 1.00 & 0.09 & 3.68 & 0 & & & \\
\hline Pancreas & 6 & 0.73 & 0.26 & 1.60 & 14 & 1.60 & 0.87 & 2.69 & 6 & 2.50 & 0.90 & 5.48 & 0 & & & \\
\hline Cervix & 26 & 1.11 & 0.72 & 1.63 & 40 & 1.63 & 1.17 & 2.23 & 8 & 1.17 & 0.50 & 2.31 & 4 & 1.42 & 0.37 & 3.68 \\
\hline Ovary & 23 & 0.98 & 0.62 & 1.48 & 31 & 1.27 & 0.86 & 1.81 & 11 & 1.62 & 0.80 & 2.91 & 3 & 1.08 & 0.20 & 3.21 \\
\hline Urinary bladder & 27 & 1.42 & 0.94 & 2.07 & 19 & 0.95 & 0.57 & 1.48 & 6 & 1.08 & 0.39 & 2.37 & 4 & 1.78 & 0.46 & 4.60 \\
\hline Thyroid gland & 11 & 0.89 & 0.44 & 1.59 & 17 & 1.35 & 0.79 & 2.17 & 1 & 0.28 & 0.00 & 1.61 & 5 & 3.40 & 1.07 & 7.99 \\
\hline Endocrine glands & 23 & 1.18 & 0.75 & 1.78 & 14 & 0.70 & 0.38 & 1.18 & 1 & 0.18 & 0.00 & 1.02 & 2 & 0.87 & 0.08 & 3.19 \\
\hline
\end{tabular}

Values in bold type indicate that $95 \%$ confidence interval $(95 \% \mathrm{Cl})$ does not include 1.00

O, observed.

vice versa. Only those sites where either the first or second comparison gave a significant result are shown. Offspring liver cancer was increased by parental cervical, bladder, and endocrine gland tumours, but none of these sites showed an excess in the reverse comparison. Offspring gall bladder cancer was increased to an SIR of 3.13 by parental liver and biliary tract cancer, and pancreatic cancer. Also, parental gall bladder cancer was increased by offspring liver and biliary (SIR 1.93) and pancreatic (1.60, 0.87-2.23) cancer. Additionally, cervical cancer in the proband associated with the risk of parental gall bladder cancer to 1.63. Cancer in extrahepatic bile ducts was increased in offspring by parental ovarian cancer to 3.83, and the SIR was above unity (1.62), even in the reverse comparison, although this was not statistically significant. Ampulla of Vater tumours were increased in parents by offspring thyroid cancer. Although not shown in table 3, it should be noted that the SIR of gall bladder cancer was 0.64 $(7,0.25-1.33)$ by parental colon cancer, and the SIR for paren- tal gall bladder cancer was $1.14(33,0.79-1.61)$ by offspring colon cancer. No evidence was found for an association between gall bladder and rectal cancer.

Gall bladder cancer was analysed specifically in table 4 against organ sites in the liver and biliary system. The only significant associations were between concordant gall bladder sites: SIRs were 5.05 for offspring and 4.09 for parents. Most familial cases involved females and the incidence of gall bladder cancer was higher in females. Yet somewhat higher SIRs were observed for offspring (of whom four were male and six were female) from mother than from father probands, and from offspring probands to mothers. We checked all cancers in the family members of the 10 affected gall bladder offspringparent pairs. The offspring had 18 siblings, of whom only one was diagnosed with cancer (a sister diagnosed with ovarian cancer at age of 23 years). The diagnostic age of the offspring with gall bladder cancer ranged from 45 to 63 years. Similar analysis was carried out on primary liver cancers, but because 
Table 4 Standardised incidence ratios (SIRs) for gall bladder cancer in offspring and parents

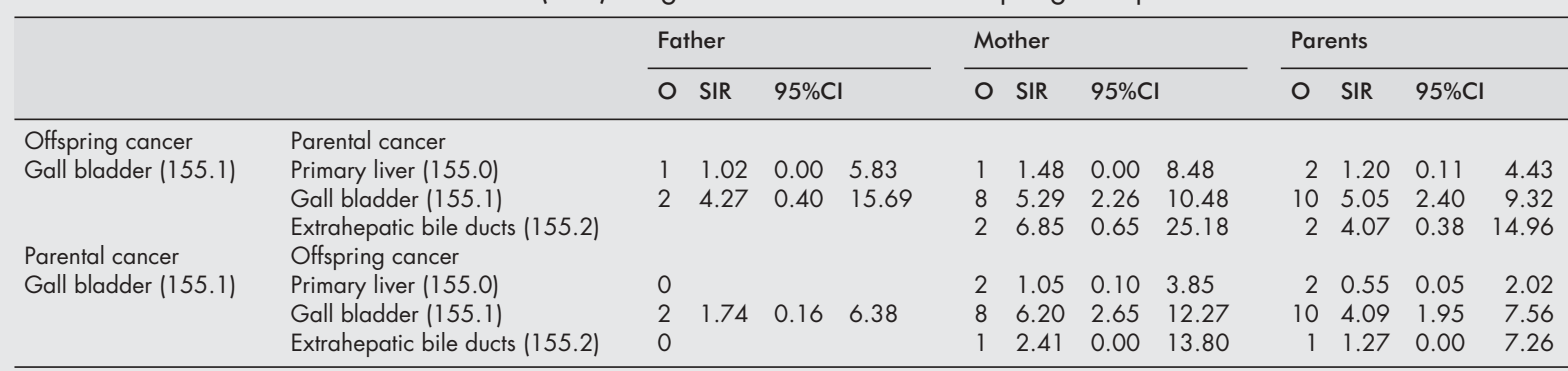

Values in bold type indicate that $95 \%$ confidence interval $(95 \% \mathrm{Cl})$ does not include 1.00

O, observed.

Table 5 Standardised incidence ratios (SIRs) for primary liver and gall bladder

cancer in offspring by parental concordant site and by liver and biliary cancer

\begin{tabular}{|c|c|c|c|c|c|c|c|c|c|}
\hline \multirow[b]{2}{*}{ Parental cancer } & \multirow[b]{2}{*}{ Histology in offspring } & \multicolumn{4}{|c|}{ Primary liver } & \multicolumn{4}{|c|}{ Gall bladder } \\
\hline & & $\mathrm{O}$ & SIR & $95 \%$ & & 0 & SIR & $95 \% \mathrm{C}$ & \\
\hline Primary liver & Hepatocellular carcinoma & 5 & 4.69 & 1.48 & 11.04 & 0 & & & \\
\hline Liver and biliary & Hepatocellular carcinoma & 7 & 2.50 & 0.99 & 5.19 & 0 & & & \\
\hline Gall bladder & Adenocarcinoma & 0 & & & & 7 & 5.21 & 2.07 & 10.80 \\
\hline Liver and biliary & Adenocarcinoma & 0 & & & & 10 & 3.28 & 1.56 & 6.06 \\
\hline
\end{tabular}

Values in bold type indicate that $95 \%$ confidence interval $(95 \% \mathrm{Cl})$ does not include 1.00 O, observed.

of the scarceness of the data, results are not shown. However, the offspring risk for primary liver cancer was 1.33 (2, 0.13-4.89) when the father had concordant cancer, while from the mother it was $4.38(4,1.14-11.32)$.

Specific histopathology (SNOMED) codes were available only for the years 1993-1998 and thus the number of familial cases was decreased (table 5). All offspring liver cancers were hepatocellular carcinomas, which showed a familial risk of $4.96(\mathrm{n}=5,95 \%$ CI $1.69-11.04)$ by parental liver cancer probands. Among the five cases, two had an affected father (SIR 3.05, 0.29-1 1.21) and three had an affected mother (7.32, 1.38-21.67). The SIR decreased to 2.50 when any parental liver or biliary tract cancer was considered in probands. Histopathology at extrahepatic organs was adenocarcinoma, of which gall bladder cancer showed an increased familial risk of 5.21 (2.07-10.80).

\section{DISCUSSION}

The Swedish Family-Cancer Database contains nationwide family data linked to the Swedish Cancer Registry. The primary aim in familial studies is to quantify familial aggregation for concordant cancer-that is, the same organ site affected in two or more related individuals. A more advanced hypothesis would be the testing of histopathological resemblance of familial cancer or of associations between discordant tumour sites. With an increasing number of tests, the number of chance associations increases. For example, the working draft for table 3 included testing of four organ sites in the liver and biliary system against 25 discordant sites-that is, 100 tests, of which five would be expected to produce a significant change at the $5 \%$ level. As we only recorded increased SIRs in table 3, two or three increases could be produced by chance. In fact, we observed six positive findings for offspring cancers and three for parental cancers. Methods for excluding chance findings are consideration of biological plausibility and consistency with previous findings. However, these offer little support because the literature is limited on familial liver and biliary tract cancers. Another possibility is to repeat the test or study, which we did, in using either parents or offspring as probands; we found this entirely independent "reverse order" testing useful, even previously. ${ }^{13} 18$ The results may not always need to agree, for example because of different age distributions for the two generations. However, if they do agree, the findings gain in credibility. Another general issue is that familial aggregation may depend on shared genes or environment, as discussed in the context of familial hepatocellular carcinoma. ${ }^{8}$ We have assessed this by comparing familial risks and spouse correlations for a number of cancers. No spouse correlation was observed for liver or biliary cancer, suggesting that shared environmental effects are small between spouses. ${ }^{18} 19$

The prevalence of risk factors for hepatocellular carcinoma is low in Sweden. The prevalence of chronic carriers of hepatitis $\mathrm{B}$ and $\mathrm{C}$ virus has been estimated at approximately $0.1 \%$ and $0.5 \%$, respectively, in the adult population, and immigrants are a risk group. ${ }^{20}$ However, hepatitis C virus is commonly associated with liver cancer in Sweden. ${ }^{21}$ Historically, per capita, alcohol consumption is low in Sweden compared with Western European levels but consumption has increased with a concomitant increase in mortality from liver cirrhosis. ${ }^{22}$ The present data on familial risks were adjusted for socioeconomic status, which should eliminate social class related differences in familial clustering for reasons such as alcohol consumption. The incidence of male primary liver appeared to be increasing towards the last observation period, covering the years 1996-1998 (fig 1). It could be speculated that increasing alcohol consumption and influx of immigrants may increase the incidence of primary liver cancer in Sweden. However, the most recent incidence data for the years 1999-2000 from the Swedish Cancer Registry show a temporary downward flux, ${ }^{3}$ suggesting that no consistent upward trend can be discerned.

The present study provided evidence on familial risks in gall bladder cancer in the 0-66 year old population of offspring. The risk to offspring from parental gall bladder cancer was high (5.05) and ranks second after thyroid cancer among all main cancers in the Family-Cancer Database. ${ }^{13}$ The SIR was even higher (5.21) when offspring gall bladder tumours were limited only to adenocarcinomas. There was a tendency for 
higher risk in women and transmission from the mother, but the number of cases was too small for definitive conclusions. Whether the familial risk is related to a possible familial propensity to gall stones remains uncertain, as are the possible shared dietary and other risk factors for gall stones. ${ }^{9}$ The relatively low risk of gall bladder cancer posed by gall stones and the lack of data on high familial risk for gall stones suggest that other more direct mechanisms may mediate the observed clustering. ${ }^{23} 24$ The only known syndrome which entails tumours at gall bladder is HNPCC, but the lack of association of gall bladder and colorectal cancer in the population or in affected families gave no indication of the involvement of this syndrome. The observed familial risk was high enough to motivate a search for susceptibility genes.

Gall bladder cancer was also associated with parental pancreatic cancer, with an SIR of 2.39. We did not observe this association in the familial study on pancreatic cancer but the gall bladder was analysed together with other liver and biliary sites. ${ }^{25}$ The association has been noted previously but the risk was given as an excessively high 9.9. ${ }^{10} \mathrm{~A}$ third association noted for gall bladder cancer was in parents from cervical cancer in daughters. However, the association was not present in the reverse analysis (offspring pancreatic cancer by mother's cervical cancer) and thus may be fortuitous.

Offspring cancer at extrahepatic bile ducts was associated with maternal ovarian cancer with an SIR (3.83) of borderline significance. However, even the reverse analyses, maternal bile duct cancer by daughter's ovarian cancer, showed an SIR above unity (1.62, 0.80-2.91), which may indicate consistency in this link. Parental ampulla of Vater tumours were increased by offspring thyroid cancer but no cases were recorded in the reverse analysis, leaving the association without additional support.

Primary liver cancer showed familial clustering when hepatocellular carcinoma histology was applied for the offspring cancers diagnosed in the period 1993-1998 (SIR 4.69, 95\% CI 1.48-11.04; table 5). However, we analyse primary liver data more cautiously than gall bladder data because only five familial liver cancer pairs were identified and there were more known environmental risk factors for liver than for gall bladder cancer. There was evidence that the transmission was mainly from the mother, which could be in line with vertical transmission of the viral infection. ${ }^{7}$ Thus the degree of heritability may be less in liver cancer. These data complete the demonstration of familial risks at all main cancer sites from the Family-Cancer Database $^{13}$ as recently even gastric, oesophageal, and pancreatic cancers were shown to exhibit familial risk from this source. ${ }^{25-27}$ The observed SIR was higher than the positive association of 2.4 from the previously cited case control study ${ }^{10}$ Primary liver cancer associated with cervical cancer in mothers, an association that has been observed previously between all liver and biliary tract cancers and cervical cancer, and that has been ascribed to lifestyle factors. ${ }^{28} 29$ The association between primary liver cancer and bladder cancer may also be explained by aggregation of alcohol and tobacco related lifestyle factors. The relation to endocrine tumours affected mainly parathyroid adenomas (SIR 2.93). This association was significant, and an increase in all liver and biliary tract tumours has been observed as second neoplasia after first parathyroid adenomas with an SIR of 1.6.

In summary, we showed a strong familial risk in gall bladder cancer and a significant familial clustering of primary liver cancer. There was limited evidenced that maternal transmission was favoured both for gall bladder and liver cancer, which may be consistent with vertical viral infection in hepatocellular carcinoma. Although environmental factors are likely to contribute, these findings call for further genetic epidemiological characterisation and challenge the search for candidate genes.

\section{ACKNOWLEDGEMENTS}

The Family-Cancer Database was created by linking registers maintained at Statistics Sweden and the Swedish Cancer Registry. The study was supported by the Swedish Cancer Society and King Gustaf V's Jubilee Fund.

..................

\section{Authors' affiliations}

K Hemminki, Department of Biosciences at Novum, Karolinska Institute, 14157 Huddinge, Sweden, and Division of Molecular Genetic Epidemiology, German Cancer Research Center (DKFZ), Heidelberg, Germany

X Li, Department of Biosciences at Novum, Karolinska Institute, 14157 Huddinge, Sweden

\section{REFERENCES}

Cancer Incidence in Sweden 1998. Stockholm: Center for Epidemiology, 2000

2 Hamilton S, Aaltonen L. Tumours of the Digestive System. Lyon: IARC 2000.

3 Cancer Incidence in Sweden 2000. Stockholm: Center for Epidemiology, 2002

4 IARC. GLOBOCAN 2000. Cancer Incidence, Mortality and Prevalence Worldwide. Lyon: IARC Press, 2001.

5 Lynch $\mathbf{H}$, de la Chapelle A. Genetic susceptibility to non-polyposis colorectal cancer. J Med Genet 1999;36:801-18.

6 Aarnio M, Sankila R, Pukkala E, et al. Cancer risk in mutation carriers of DNA- mismatch-repair genes. Int J Cancer 1999;81:214-8.

7 Yu MW, Chang HC, Liaw YF, et al. Familial risk of hepatocellular carcinoma among chronic hepatitis B carriers and their relatives. J Natl Cancer Inst 2000;92:1159-64.

8 Petersen G. Familial aggregation: sorting susceptibility from shared environment. J Natl Cancer Inst 2000;92:1 114-5.

9 Sheth S, Bedford A, Chopra S. Primary gallbladder cancer: recognition of risk factors and the role of prophylactic cholecystectomy. Am J Gastroenterol 2000;95: 1402-10

10 Fernandez E, La Vecchia C, D'Avanzo B, et al. Family history and the risk of liver, gallbladder, and pancreatic cancer. Cancer Epidemiol Biomarkers Prev 1994:3:209-12.

11 Goldgar DE, Easton DF, Cannon-Albright LA, et al. Systematic population-based assessment of cancer risk in first-degree relatives of cancer probands. J Natl Cancer Inst 1994;86:1600-7.

12 Vaittinen $\mathbf{P}$, Hemminki K. Familial cancer risks in offspring from discordant parental cancers. Int J Cancer 1999;81:12-19.

13 Dong C, Hemminki K. Modification of cancer risks in offspring by sibling and parental cancers from 2,112,616 nuclear families. Int J Cancer 2001;91:144-50

14 Hemminki K, Li X, Plna K, et al. The nation-wide Swedish Family-Cancer Database: updated structure and familial rates. Acta Oncol 2001;40:772-7.

15 Hemminki K. Genetic epidemiology: science and ethics on familial cancers. Acta Oncol 2001:40:439-44.

16 Ekstrom AM, Signorello LB, Hansson LE, et al. Evaluating gastric cancer misclassification: a potential explanation for the rise in cardia cance incidence. J Natl Cancer Inst 1999;91:786-90.

17 Hemminki K, Li X. Familial risk of cancer by site and histopathology. Int J Cancer 2003; 103:105-9.

18 Hemminki K, Jiang Y. Cancer risks among long-standing spouses. Br J Cancer 2002:86:1737-40.

19 Hemminki K, Dong C, Vaittinen P. Cancer risks to spouses and offspring in the Family-Cancer Database. Genet Epidemiol 2001;20:247-57.

20 Hoffmann G, Berglund G, Elmstahl S, et al. Prevalence and clinical spectrum of chronic viral hepatitis in a middle-aged Swedish general urban population. Scand J Gastroenterol 2000;35:861-5.

21 Widell A, Verbaan H, Wejstal R, et al. Hepatocellular carcinoma in Sweden: its association with viral hepatitis, especially with hepatitis $C$ viral genotypes. Scand J Infect Dis 2000;32:147-52.

22 Ramstedt M. Per capita alcohol consumption and liver cirrhosis mortality in 14 European countries. Addiction 2001;96(suppl 1):S19-33.

23 Zatonski WA, Lowenfels $A B$, Boyle $P$, et al. Epidemiologic aspects of gallbladder cancer: a case-control study of the SEARCH Program of the International Agency for Research on Cancer. J Natl Cancer Inst 1997:89:1132-8

24 Chow WH, Johansen C, Gridley G, et al. Gallstones, cholecystectomy and risk of cancers of the liver, biliary tract and pancreas. $\mathrm{Br} J$ Cancer 1999;79:640-4.

25 Hemminki K, Li X. Familial and second primary pancreatic cancers: a nation-wide epidemiologic study from Sweden. Int J Cancer 2003;103:525-30.

26 Hemminki K, Jiang Y. Familial and second gastric cancers: a nation wide epidemiologic study from Sweden. Cancer 2002;94:1 157-65.

27 Hemminki K, Jiang Y. Familial and second esophageal cancers: a nation-wide epidemiologic study from Sweden. Int J Cancer 2002;98:106-9.

28 Hemminki K, Dong C, Vaittinen P. Familial risks in cervix cancer: is there a hereditary component? Int J Cancer 1999;82:775-81.

29 Hemminki K, Li X, Mutanen P. Familial risks in invasive and in situ cervical cancer by histological type. Eur J Cancer Prev 2001;10:83-9.

30 Hemminki K, Jiang Y. Second primary neoplasms after 19281 endocrine gland tumours: aetilogical links? Eur J Cancer 2001;37: 1886-94. 